\title{
The Impacts of Dry \& Wet Seasons Induced Criteria Air Pollutants Concentrations in Old Port Harcourt Gra, Rivers State, Nigeria
}

\author{
Levi-Okoli Ifeyinwa Chikerenma ${ }^{1}$; Briggs-Kamara Apaemi ${ }^{2}$; \\ Sigalo Friday Barikpe ${ }^{3}$; Iyeneomie Tamunoobereton-Ari ${ }^{4}$ \\ ${ }^{1,2,3,4}$ Department of Physics, Faculty of Science, Rivers State University, Port Harcourt, Nigeria \\ Corresponding Author: Levi-Okoli Ifeyinwa Chikerenma
}

\begin{abstract}
This paper evaluated the air quality in Old Port Harcourt GRA in order to determine if it is within or above the acceptable limits/standards by the WHO. To measure the ambient air quality in the study area, a portable gaseous emission analyzer was used. Gaseous pollutants were monitored continuously by pulsed fluorescence. In this method, air is drawn via a sample chamber where it is irradiated with pulses of ultra-violet light. Any specified gas of interest in the sample is excited to a higher energy level and upon returning to its original state, light or fluorescence is released. The amount of fluorescence measured is proportional to the gas concentration. The Suspended particulate matter was measured with an EGVOC SPM Monitor. This is a hand held Aerosol particle counters that operates by counting and sizing the number of particles in the air. In the data analysis, all the average measurements were done in uniform unit of $\mu \mathrm{g} / \mathrm{m}^{3}$. From the findings, in Old Port Harcourt GRA, the ozone $\left(\mathrm{O}_{3}\right)$ for both dry and wet seasons, and wet season $\mathrm{PM}_{10}$ were within the WHO standards. Sox for both wet and dry seasons were above the WHO limit by $80 \%$; NOx for both wet and dry seasons were above WHO limits by $60 \%$. However, the mean concentration of $\mathrm{PM}_{2.5}$ in dry season was above the WHO limits by $88.2 \%$, while in wet season, the average concentration of $\mathrm{PM}_{2.5}$ was higher than the WHO limits by just $11.5 \%$. The average concentration of $\mathrm{PM}_{10}$ in dry season was higher than the WHO limits by $79.5 \%$. The implications of the findings are that the levels/concentrations of the ozone $\left(\mathrm{O}_{3}\right)$ both in the dry and wet seasons and the $\mathrm{PM}_{10}$ level in wet season are safe enough for the people of old Port Harcourt GRA as they are within the WHO standards for criteria air pollutants. The level of $\mathrm{PM}_{2.5}$ in wet season is relatively safe but more works still need to be done to further reduce it to be within WHO acceptable limits. The levels/concentrations of the other criteria air pollutants are very unsafe for the people of old Port Harcourt GRA.
\end{abstract}

Keywords: Criteria air pollutants, Wet season, Dry Season, Port Harcourt, WHO guidelines.

\section{INTRODUCTION}

Clean air is viewed as a fundamental necessity of human wellbeing. Be that as it may, air contamination keeps on representing a critical danger to wellbeing of people around the world. As per a WHO appraisal of the weight of infection because of air contamination, over 2 million unexpected deaths every year can be attributed to the impacts of metropolitan outdoor air contamination. The greater part of this pollution burden is borne by the people of developing nations. Outdoor air contamination is a significant ecological health issue impacting on people in low, middle, and high income nations. Ambient (outdoor) air contamination in both urban and rural areas was assessed to cause 4.2 million unexpected deaths globally each year in 2016; this mortality is because of exposure to small particulate matter of 2.5 microns or less in size $\left(\mathrm{PM}_{2.5}\right)$, which cause 
cardiovascular and respiratory ailments, and cancers. Individuals living in low and middle-income nations excessively experience the burden of outdoor air contamination with $91 \%$ (of the 4.2 million unexpected deaths) happening in low and middle-income nations like Nigeria (Cohen, 2004; WHO, 2006).

More proofs showing the linkages between ambient air contamination and the cardiovascular ailment risks is coming up, including researches from profoundly contaminated regions. WHO estimates that in 2016, some $58 \%$ of outdoor air contamination-related unexpected deaths were because of ischaemic coronary illness and strokes, while $18 \%$ of deaths were because of chronic obstructive pulmonary disease and acute lower respiratory diseases respectively, and $6 \%$ of deaths were because of cancer of the lungs (Pope, 2002).

A number of deaths might be credited to more than one risk factor simultaneously. For instance, both smoking and surrounding air contamination impact on cancer of the lungs. Some lung cancer deaths might have been avoided by enhancing ambient air quality, or by decreasing tobacco smoking (WHO, 2006).

A 2013 appraisal by WHO's International Agency for Research on Cancer (IARC) inferred that outdoor air contamination is cancer-causing to people, with the particulate matter part of air contamination most firmly connected with elevated cancer incidence, particularly cancer of the lungs. A connection additionally has been seen between outdoor air contamination and elevation in urinary tract/bladder cancer.

Addressing all risk factors for nontransmittable illnesses - including air contamination - is critical to securing public wellbeing. A sizeable number of outdoor air contaminations are definitely past the control of people and requires deliberate action by local, national and regional level policy makers working in areas like transport, energy, waste management, urban planning, and agriculture.
Air contaminant concentrations ought to be estimated at monitoring sites that are representative of population exposures. Air contamination levels might be higher close to the specific sources of air contamination, like streets, power plants and large stationary sources, thus safe guarding of the people living in such circumstances may demand unique measures to bring the contamination levels to beneath the WHO guideline values.

By decreasing air contamination levels, nations can lessen the weight of disease from stroke, heart disease, cancer of the lungs, and both chronic and acute respiratory infections, including asthma. The lower the degrees of air contamination, the better the cardiovascular and respiratory wellbeing of the people will be, both longand short-term. This paper evaluated the air quality in Old Port Harcourt GRA in order to determine if it is within or above the acceptable limits/standards by the WHO. The outcome of this paper will assist government with the development of laws and environmental legislations to reduce the concentrations of the criteria air pollutants to be within WHO guidelines and acceptable limits.

\section{CRITERIA AIR POLLUTANTS Particulate matter}

The proof on airborne particulate matter (PM) and its public health impact is consistent in showing negative health impacts at exposures that are right now experienced by urban populations in both developed and developing nations. The scope of health impacts is broad, however are overwhelmingly to the respiratory and cardiovascular systems. All population is impacted on, however vulnerability to the contamination may vary with health or age. The risk for different results has been demonstrated to elevate with exposure. Air quality estimations are regularly reported in terms of daily or yearly mean concentrations of $\mathrm{PM}_{10}$ particles per cubic meter of air volume $\left(\mathrm{m}^{3}\right)$. Routine air quality estimations commonly depict such PM concentrations in 
terms of micrograms per cubic meter $(\mu \mathrm{g} / \mathrm{m} 3)$. At the point when adequately sensitive estimation tools are accessible, concentrations of fine particles $\left(\mathrm{PM}_{2.5}\right.$ or smaller), are additionally reported. Small particulate contamination has health impacts even at extremely low concentrations - in fact no limit has been recognized below which no harm to health is noticed (WHO, 2006; Katsouyanni, 2001).

The WHO rules for particulate matter are (WHO, 2005):

$\mathrm{PM}_{2.5}: 10 \mu \mathrm{g} / \mathrm{m}^{3}$ yearly mean

$25 \mu \mathrm{g} / \mathrm{m}^{3}$ 24-hour mean

$\mathrm{PM}_{10}: 20 \mu \mathrm{g} / \mathrm{m}^{3}$ yearly mean

$50 \mu \mathrm{g} / \mathrm{m}^{3} 24$-hour mean

\section{Ozone}

Ozone is formed in the air by photochemical reactions within the presence of sunlight and precursor pollutants, like the oxides of nitrogen (NOx) and volatile organic compounds (VOCs). It is obliterated by reactions with $\mathrm{NO} 2$ and is deposited to the ground. A number of investigations have revealed that ozone concentrations correspond with different other harmful photochemical oxidants emerging from comparable sources, including the peroxyacyl nitrates, nitric acid and hydrogen peroxide. Measures to manage tropospheric ozone levels center its precursor gas emissions, however are probably going to also control the levels and effects of some of these other contaminants. There are some proves that long-term exposure to ozone may have chronic impacts (WHO, 2006).

The WHO standard for ozone is (WHO, 2005): $100 \mu \mathrm{g} / \mathrm{m}^{3}$ 8-hour mean.

\section{Nitrogen dioxide}

Evidence has arisen that elevates the worry over health impacts related with outdoor air contamination mixtures that incorporate $\mathrm{NO}^{2}$. For example, epidemiological examinations have revealed that bronchitic symptoms of asthmatic kids elevate in relation with yearly $\mathrm{NO}_{2}$ concentration, and that decreased lung function growth in kids is connected to raised $\mathrm{NO}_{2}$ concentrations (Burnett, 2004).

The WHO standards for $\mathrm{NO}_{2}$ are (WHO, 2005):

$40 \mu \mathrm{g} / \mathrm{m}^{3}$ yearly mean

$200 \mu \mathrm{g} / \mathrm{m}^{3}$ 1-hour mean

\section{Sulfur dioxide}

Controlled investigations comprising exercising asthmatics demonstrate that a portion experience variations in pulmonary function and respiratory symptoms after times of exposure to $\mathrm{SO}_{2}$ as short as 10 minutes. Researches demonstrate that a portion of individuals with asthma experience variations in pulmonary function and respiratory symptoms after times of exposure to $\mathrm{SO}_{2}$ as short as 10 minutes. Health impacts are currently known to be related with much lower levels of $\mathrm{SO}_{2}$ than earlier believed. A more significant level of protection is required. Albeit the causality of the impacts of low concentrations of $\mathrm{SO}_{2}$ is still uncertain, lessening $\mathrm{SO}_{2}$ concentrations is probably going to diminish exposure to co-contaminants (WHO, 2006).

The WHO guidelines for Sulphur dioxide are (WHO, 2005):

$20 \mu \mathrm{g} / \mathrm{m}^{3}$ 24-hour mean

$500 \mu \mathrm{g} / \mathrm{m}^{3} 10$-minute mean

\section{METHODOLOGY \\ Study Area}

This study was conducted in old Port Harcourt GRA. As a multi-purpose location, Old GRA serves as residential, recreational and business location. The area is surrounded to the east by Abuloma, to the north by the D-line area, to the west by Diobu and Kidney Island and to the south by Borokiri. It is made up of the areas within the Zip code 500241 (see Figure 1). 


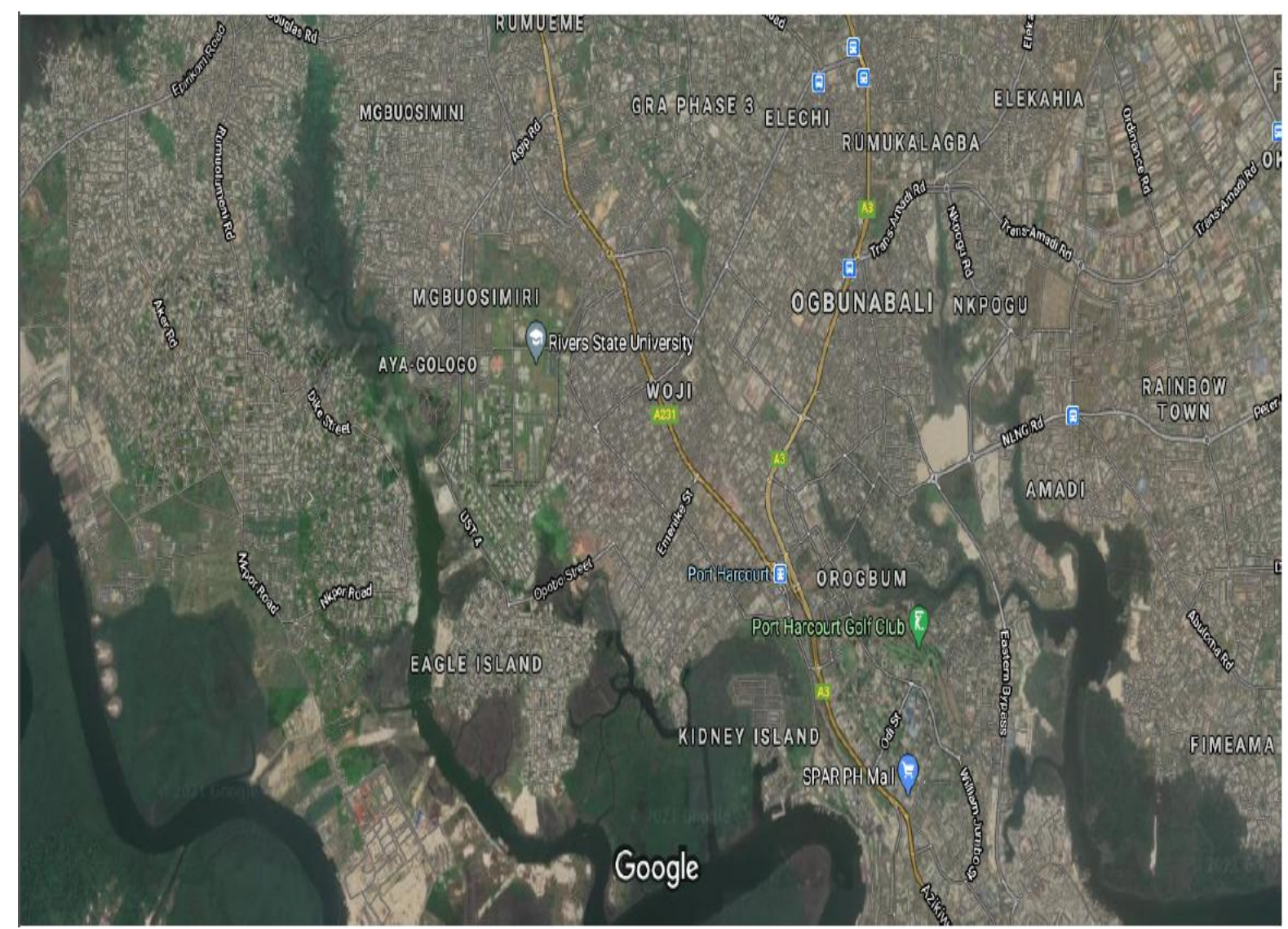

Figure 1: Map of Old Port Harcourt GRA.

\section{AMBIENT AIR QUALITY MEASUREMENT}

To measure the ambient air quality in the study area, a portable gaseous emission analyzer was used. The BOSEAN Gas Detector collects and stores data independently. The functionalities comprise a menu driven user interface and LCD display. The meter is manufacturer calibrated and also has self-auto calibration. Gaseous pollutants are monitored continuously by pulsed fluorescence. In this method, air is drawn via a sample chamber where it is irradiated with pulses of ultraviolet light. Any specified gas of interest in the sample is excited to a higher energy level and upon returning to its original state, light or fluorescence is released. The amount of fluorescence measured is proportional to the gas concentration.

The Suspended particulate matter was measured with an EGVOC SPM Monitor. This is a hand held Aerosol particle counters that operates by counting and sizing the number of particles in the air.

\section{RESULT \& DISCUSSION}

Table 1: Wet and Dry Seasons Concentrations of Criteria Air Pollutants in Borokiri, Port Harcourt

\begin{tabular}{|c|c|c|c|c|c|c|c|c|c|c|c|c|c|}
\hline \multicolumn{14}{|l|}{ LOCATION : OLD GRA } \\
\hline \multirow[t]{2}{*}{ Parameters } & \multicolumn{9}{|c|}{ DRY SEASON } & \multicolumn{4}{|c|}{ WET SEASON } \\
\hline & $\begin{array}{l}12: 10 \\
\mathrm{pm}\end{array}$ & $\begin{array}{l}12: 55 \\
\mathrm{pm}\end{array}$ & $\begin{array}{l}1: 40 \\
\text { pm }\end{array}$ & $\begin{array}{l}2: 25 \\
\text { pm }\end{array}$ & $\begin{array}{l}1: 40 \\
\mathrm{pm}\end{array}$ & $\begin{array}{l}2: 10 \\
\text { pm }\end{array}$ & $\begin{array}{l}2: 40 \\
\text { pm }\end{array}$ & $\begin{array}{l}3: 10 \\
\text { pm }\end{array}$ & Average & $\begin{array}{l}11: 11 \\
\text { am }\end{array}$ & $\begin{array}{l}11: 41 \\
\text { am }\end{array}$ & $\begin{array}{l}12: 11 \\
\mathrm{pm}\end{array}$ & Average \\
\hline $\mathrm{SO}_{\mathrm{X}},(\mathrm{ppm})$ & $<0.1$ & $<0.1$ & $<0.1$ & $<0.1$ & $<0.1$ & $<0.1$ & $<0.1$ & $<0.1$ & $<0.1$ & $<0.1$ & $<0.1$ & $<0.1$ & $<0.1$ \\
\hline $\mathrm{NO}_{\mathrm{X}}(\mathrm{ppm})$ & $<0.1$ & $<0.1$ & $<0.1$ & $<0.1$ & $<0.1$ & $<0.1$ & $<0.1$ & $<0.1$ & $<0.1$ & $<0.1$ & $<0.1$ & $<0.1$ & $<0.1$ \\
\hline Ozone $\left(\mathrm{O}_{3}\right)(\mathrm{ppm})$ & $<0.1$ & $<0.1$ & $<0.1$ & $<0.1$ & $<0.1$ & $<0.1$ & $<0.1$ & $<0.1$ & $<0.1$ & $<0.1$ & $<0.1$ & $<0.1$ & $<0.1$ \\
\hline $\begin{array}{l}\text { Particulate matter } \mathrm{PM}_{2.5} \\
\left(\mu \mathrm{g} / \mathrm{m}^{3}\right)\end{array}$ & 122 & 101 & 94 & 88 & 66 & 70 & 77 & 58 & 84.5 & 7 & 13 & 14 & 11.3 \\
\hline $\begin{array}{l}\text { Particulate matter } \mathrm{PM}_{10} \\
\left(\mu \mathrm{g} / \mathrm{m}^{3}\right)\end{array}$ & 140 & 117 & 109 & 102 & 76 & 81 & 89 & 67 & 97.7 & 8 & 15 & 16 & 13 \\
\hline
\end{tabular}




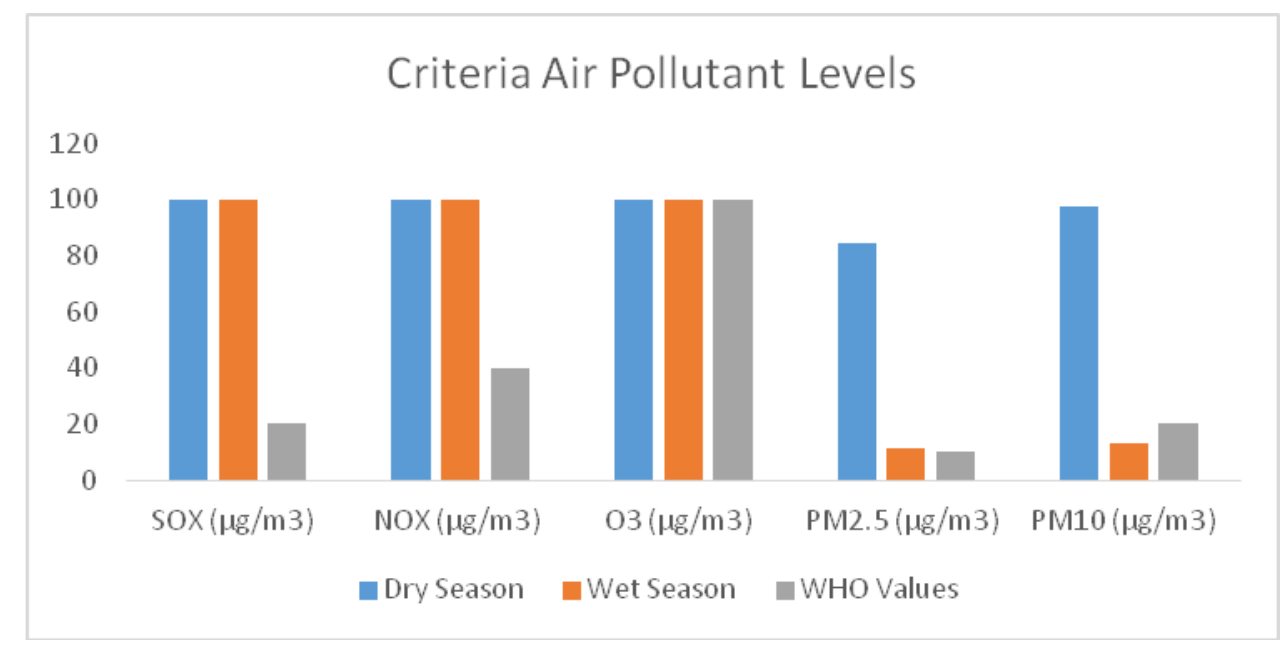

Figure 2: Average Concentrations of criteria air pollutants in dry and wet season in Old Port

\section{Harcourt GRA compared to WHO guidelines}

All the average measurements were done in uniform units of $\mu \mathrm{g} / \mathrm{m}^{3}$. From Figure 2, in Old Port Harcourt GRA, the ozone $\left(\mathrm{O}_{3}\right)$ for both dry and wet seasons, and wet season $\mathrm{PM}_{10}$ were within the WHO standards. Sox for both wet and dry seasons were above the WHO limit by $80 \%$; NOx for both wet and dry seasons were above WHO limits by $60 \%$. However, the mean concentration of $\mathrm{PM}_{2.5}$ in dry season was above the WHO limits by $88.2 \%$, while in wet season, the average concentration of $\mathrm{PM}_{2.5}$ was higher than the WHO limits by $11.5 \%$. The average concentration of PM10 in dry season was higher than the WHO limits by $79.5 \%$.

\section{CONCLUSION}

As per the findings, the levels / concentrations of the ozone $\left(\mathrm{O}_{3}\right)$ both in the dry and wet seasons and the PM10 level in wet season are safe enough for the people of old Port Harcourt GRA as they are within the WHO standards for criteria air pollutants. The level of $\mathrm{PM}_{2.5}$ in wet season is relatively safe but more works still need to be done to further reduce it to be within WHO acceptable limits. The levels / concentrations of the other criteria air pollutants are very unsafe for the people of old Port Harcourt GRA.

\section{Acknowledgement: None}

Conflict of Interest: None

Source of Funding: None

Ethical Approval: Approved

\section{REFERENCES}

1. Burnett R.T. (2004). Associations between short-term changes in nitrogen dioxide and mortality in Canadian cities. Archives of Environmental Health, 59:228-236.

2. Cohen A. (2004). Mortality impacts of urban air pollution. In: Ezzati $\mathrm{M}$ et al., eds. Comparative quantification of health risks: global and regional burden of disease attributable to selected major risk factors. Geneva, World Health Organization: 1353-1434.

3. Katsouyanni K. (2001). Confounding and effect modification in the short-term effects of ambient particles on total mortality: results from 29 European cities within the APHEA2 project. Epidemiology, 12:521-531.

4. Pope C.A. (2002). Lung cancer, cardiopulmonary mortality, and longterm exposure to fine particulate air pollution. Journal of the American Medical Association, 287:1132- 1141.

5. WHO (2006). Air quality guidelines of WHO for particulate matter, ozone, nitrogen dioxide and sulfur dioxide. Global update 2005. WHO/SDE/PHE/OEH/06.02, World 
Levi-Okoli Ifeyinwa Chikerenma et.al. The impacts of dry \& wet seasons induced criteria air pollutants concentrations in Old Port Harcourt Gra, Rivers state, Nigeria.

Health Organisation. http:whqlibdoc.who.int/hq/2006/WHO_ SDE_PHE_OEH_06.02_eng.pdf.

6. WHO. (2005). Air Quality Guidelines for Particulate Matter, Ozone, Nitrogen dioxide and Sulfur dioxide. Global Update. World Health Organisation.
How to cite this article: Levi-Okoli Ifeyinwa Chikerenma; Briggs-Kamara Apaemi; Barikpe SF et.al. The impacts of dry \& wet seasons induced criteria air pollutants concentrations in Old Port Harcourt Gra, Rivers state, Nigeria. Int J Health Sci Res. 2021; 11(5): 255-260. DOI: https://doi.org/ 10.52403/ijhsr.20210541 